\title{
Social Media and Pakistani Journalists: WhatsApp Usage for News and Ethical Performance
}

\author{
Dr. Wajid Zulqarnain ${ }^{1} \quad$ Naveed Ullah Hashmi ${ }^{2} \quad$ Amna Zulqarnain ${ }^{2}$ \\ 1.Assistant Professor/HoD Media Sciences, SZABIST Islamabad Campus \\ 2.Lecturer, SZABIST Islamabad Campus
}

\begin{abstract}
With the fast expansion and acceptance of the Social Media in Pakistan, it is observed that the traditional journalism has entered in a new avenue because social media not only facilitating networking platform for the communities but also it has also been becoming a source of news for the traditional media journalists. As previous studies discussed that social media including Twitter and Facebook become the important tool to disseminate the news. Previous researches are the evidence of the usage of social media as a news source however they also pointed out the questions of the credibility of the information provided by these social media sites, including Facebook, Twitter, YouTube, Instagram and WhatsApp therefore the objective of this study is to find out how social media especially WhatsApp is being used as source of information for the journalists working in the traditional media and to what extent it is influencing the ethical performance of the journalists in Pakistan. This will be a qualitative study in which interview technique is employed and theoretical framework has been used based on the diffusion of innovation theory. Population of the study is all the news TV channels in Pakistan. Sample of the study will be ten field reporters and news room personnel from one private and one public main stream news TV channels of Pakistan. The results show that the Journalists, newsroom personnel and reporters use WhatsApp because of its extra ordinary features to enhance their reporting magnitude. Results also show that journalists and reporters ignore ethical rules and regulations during the reporting and in field even they are aware of rules and regulations of journalism.

Keywords: Online media, journalists, news, diffusion of innovation, credibility, ethical performance, WhatsApp DOI: $10.7176 / \mathrm{NMMC} / 88-02$

Publication date: February $29^{\text {th }} 2020$

\section{Context and Issues}

Wolcott and Goodman (2000) discussed that at the beginning of 1995 the internet launched in Pakistan, whereas the main boost started from 1999 with 100 internet Services providers. The internet users rapidly increased with time to time in Pakistan however 0.5 percent of total population has access in Pakistan in 2000. Gallup (2013) reported that these percentages change into $51 \%$ students used internet however and $30 \%$ house hold females used internet for entertainment by the end of 2013. As Kemp (2018) discussed that in 2018 the internet users increase by $22 \%$ of total population, similarly for twitter, WhatsApp and Facebook this percentage is $55 \%$ and $25 \%$ use internet for news gathering.
\end{abstract}

\section{Social media and Journalism}

Lin and Lu (2011) found that Social networking sites have become widespread and since the establishment of Social networking sites many users have been attracted to this internet world. Many of these sites, such as Myspace, Facebook, and Pinterest have been incorporated into daily practices of users. Boulos at. el (2016) explained that for learning and collaboration opportunities to busy professionals of different fields and peer-topeer support, smart phones, tablets and mobile apps are important development in different fields, particularly social applications.

Boulos at. el (2016) discussed that many "communication portal" has been established for social networking, which can see in the form of Facebook, Twitter and WhatsApp for communication. By using these types of social media group on social media platform fruitful and information-sharing activities conducted via online discussions.

As indicated by the Global Digital Report (2018) there are 3.2 billion users of Facebook, YouTube, WhatsApp and Twitter. In Pakistan, 35 million individuals, or around 18 percent of the population are the users of Social Media. Shah (2018) explored that nowadays television is not just only mean of spreading fake news, but with the advent of social media fake stories get viral through posts on Facebook, melodramatic messages on WhatsApp and as such news are off base and far away from reality. Different research considered that WhatsApp is also the plate form which connects different people together individually and group wise (Alsanie, 2015).

Boulos at. el (2016) found that for discussing and sharing different issues between the members of social groups, social media trend has been followed, which also engaged audience for seeking knowledge through Instagram and WhatsApp. Khan (2017) explained that WhatsApp has significantly become trendy text 
messaging technology because of it consent to free exchange of text, pictures, videos and documents. Moreover, journalist uses different social media including twitter, WhatsApp and other networking site to gather and disseminate information and news (Avery et al., 2010).

According to Arshad and Ashraf (2014), these new technology advancements is making the life of journalists very simple as it gives help to tackle the practices of journalists burden in Pakistan. The new technology such as digital application like WhatsApp is a one that influenced largely in the journalists practices of news. As in new era of journalists, this digital technology is fulfilling their needs of communication information

Wainaina (2016) mentioned that Kenya ministers are also sharing their unique knowledge towards their journalists with the support of WhatsApp technology application. In Asia, specifically after the WhatsApp emergence, this is considered as the reliable and good use of technology application.

Cohen (2016) mentioned that Media organizations however using WhatsApp to provide their news stuff and beats etc. Siapera (2012) elaborates here that the field of journalism is now much known that the practices of traditional media are no more useful in the completion of communication. WhatsApp quickly replaces the easy tool of dissemination of information and also the news. The reason of its simple and quick use, Pakistani journalist's now also realizing importance of WhatsApp (advanced messaging application). They are also sharing their images towards others and recordings exchange to their colleagues, recordings of voice, news reports and more work can be done through quick social medium like WhatsApp. Brown et al. (2015) mentioned that this application like WhatsApp is increasing learning grounds and it is best and suitable for the journalist which shaping the advance journalism practices. A study by Pew research center (2010) further explains that due to the huge effect of WhatsApp, it emerged the global phenomena and it also supported the advancement of application correspondence which is usage of promises comfort to its users and it also impact in journalism field in largely.

Social media tool "Twitter" is one of the most utilizing tools for the News dissemination by the journalist (Ahmad, 2010). However, WhatsApp also considered as top-rated social media tools to spreading of means (Alsanie, 2015). Sense of professionalism modified the view point of world against Pakistani Journalists as they tried to facilitate the sovereignty of nation and boost the social development. On the same time, it is catalyst of dissemination of fake news (Pintak \& Nasir, 2013).

These all journalistic approaches and scenario raises a valid question that to what extent the ethical journalistic performance practices while using WhatsApp for news writing on traditional media.

\section{Literature Review}

According to Silvestre (2011) online media create news dynamic of virtual social gather and provide a plate form to interact between groups or other individuals which allow to communication through video, audio, text and in form of opinions. Hou and Lampe (2015) elaborate the platforms including Facebook, tweeter, WhatsApp and LinkedIn, which is very widely used and it acquire and share the new information and in relationship building. It is also useful tool to aware the campaigns over the world with the help of online communications reach and constraint of space. Twitter is one of the professional social networking platforms to interact with professionals of same fields, where student also share their photos, quotes, video and news between their groups Bicen and Cavus (2012).

Hansen, at el. (2010) explains that instant message application is available in form of a multi-platform that is called WhatsApp. It is also an application which helps its users for sending and taking knowledge, it includes the text, images, messages and voice calls etc. WhatsApp has become more than millions of 500 users active in a month and exchanged more than 100 million videos and 700 million photos a day and the messaging system sends more than 10 billion messages a day.

After US election 2016 a new issue of fake news was appeared which spread through social media. The research found that in last three months of US election, the source of news penetration was from false website and blogs. Moreover, these stories were shared by the mainstream media frequently and generate 8.7 million shares, comment and likes (Silverman, 2016). During January 2015 to July 2018, total 570 fake news websites disseminate fake news and total 10240 fake news stories disseminate between the twitter and Facebook users. However (Allcott, at el., 2018)

\subsection{Performance of Journalists and Fake news}

Fake news played as catalyst against the distrust of public institution (Nicolaou \& Giles, 2017). Fake news also reduced not only the credibility of traditional news journalism but also the degeneration of professional news journalists (Clark \& Marchi, 2017), however the participatory style of user in social media promote the content in digital culture of (Grossman, 2006; Mitchem, 2008). Characteristic of social media and participatory role of its uses opted vital changes in the traditional news media while sharing and reporting news stories, news and current affairs among the young people (Greenhow \& Reifman, 2009). Similarly, digital media also assist to increase the 
rate of news distribution. At the same time a question raise that what is news and what fake news is. According to the Wardle (2017) false connection, false context, manipulated content, satire or parody, misleading content, imposter content and fabricated content are considered as fake news.

Bogle (2018) reported that true news are less in number on twitter as compare to false news and have faster, deeper and broadly spread between 2006 and 2017. However, Dr Vosoughi discussed that the creativity and uniqueness of false motives its reader to share more frequently and more effort is required in creating sense of awareness and inspirations for users who share the information.

Dutton (2013) Focus on four types of news practices, namely: (a) editing process modifications, (b) alternatives to news gathering practices, (c) time-mode acceleration of production, and finally the integration of printing, electronics and online operations, among which personnel. Explore new alternatives to news gathering practices such as "WhatsApp". According to the Reid (2014) WhatsApp is the best tool to get access and disseminate information either true or false to poor people. Unbiased, positive reporting, debate and discussion are the true souls of journalism, and it can build an optimistic and healthy democratic society. Citizens participate in the news process and exchange the whole of traditional news media. Attitude, traditional news media is seen as the gatekeeper of information. Kolodzy (2006) believed that some news become the participatory news where producers, consumers and audience become the part of the news through conversation, similarly audience sometimes decides to share the news with each other and defame the traditional news style. Communication is becoming more and more personalized, and people's opinions are increasingly influenced by the media. Communication theory explains that there is a message to send and the media and information receivers. Today, the recipient itself has become the sender.

Riaz and Pasha (2011) explain that they have become the disseminators of information, and of course there are opinions. There are plenty of opportunities in this situation. However, from a real point of view, the truth here may be a bit confusing when examined more rigorously. Sometimes it is difficult to navigate through these vague truths.

Nyabuga (2016) mentioned that in Pakistan, a huge challenge is that the scarcity of relocation assistance for journalists is initially limited to one month and can be extended to up to three months of support. However, the threat of driving journalists into temporary exile usually does not disappear within a month or even three months. In addition, when journalists are unable to work due to relocation, they need financial support during this period. At the time of writing, Pakistan did not have adequate and effective mechanisms, including specific agencies, programmes and budgets, to monitor and report threats, harassment and violence against journalists. There are no clear policies at the federal or provincial level that outline the protection or pre-emptive measures of journalists or media agencies, or the allocation of designated resources and expertise to provide institutionalized support to attacked or troubled media practitioners.

In the case of Pakistan, Huang (2016) explained that according to the Committee for the Protection of Journalists (CPJ), Pakistan is the fourth most deadly country for journalists, where sensitive or serious news reports and news reports are punishable by the deaths of unknown groups (AFP 2016). Dawn newspaper editor Zafar Abbas takes the "WhatsApp"; program to protect the lives of journalists. However, Huang (2016) found that the found of WhatsApp Jan Koum and Brain Acton stated that the main concern of this application is to make the users data and communication safer and more encrypted, this feature feel its users especially journalist more secure than before.

Caetano at el. (2018) mentioned that as of 2018, WhatsApp is an important part of the global information and communication infrastructure, especially in developing countries. However, due to its powerful end-to-end encryption, WhatsApp has become an attractive place to spread misinformation, extremism and other forms of bad behavior. However, Greenberg (2014) explained that WhatsApp "has unique features with end-to-end encryption. Improvements to its confidentiality make it easy for anyone to understand the communication between writing and reading users (journalists) - even independent groups - is almost infeasible. Innovative encryption systems mean " WhatsApp communication will now port all methods to the receiver's gadget before using the "WhatsApp" server to encode in the user's gadget.

Azeema and Nazuk (2017) revealed that journalists not only use "WhatsApp" to chat, but they also gain practical benefits by using this sms application in professional practice. "WhatsApp" may become a new app for journalists to help them with the instant news gathering process. Moreover, it also leads to penetrate the fake news in journalists' society which ultimately becomes the national news.

The study focused on the normal journalistic approach in the era of online journalism and speedy informative access. According to Singer (2005) the main challenge of the journalists is not only using the gatekeeping ideology between the information and its users but also the format of the news that enhance the percentage of transparency and accountability.

According to Lacy and Rosenstiel (2015) and McQuail (1992), the quality of journalism can be measure through unit of analysis such as story, news and news market and news organization and performance of journalists instead of audience perception or professional journalists' standards. 
Different scholars, organization and institutes discuss the professional journ;EEalistic qualities differently however the IREX give the detail to identify professional journalism quality standards on the bases of different levels. At first level fair, objective and well sourced reporting followed by use of recognized and accepted ethical standards by journalists, at third level IREX discuss lack of self-censorship, on fourth, fifth, six and seven level IREX discussed focused on issues and key events, discourage corruption and maintain qualified personnel, news and information instead of entertainment and adequate technical facilities, at last level impressive reporting like investigative, economics, business etc. (IREX, 2014).

To appraise these levels developed by IREX, UNESCO's Media Development Index developed five categories. First category is about the system to regulate the freedom of expression, second discuss the relationship between transparency and economic level, democratic discourse through media, journalists training, education and professional development to boost their careers, infrastructural contribution to support and sever for all the group without any discrimination and difference (IREX, 2014).

Atkinson (2010) discussed the three criteria to evaluate the journalist's performance including ethical performance, commercial performance and theatrical performance. Ethical performance depends on four main factors which are long-term benefits to society, needs and (inclusive) rights, collective goals (democracy, learning, participation, engagement) and substantive message content over format and distribution. Commercial and theatrical performance is to some extend based on the ethical performance of the journalist, therefore the current research is based on the ethical performance of the journalist through the lens of WhatsApp.

\section{Theoretical frame work}

White (2012) adopted diffusion of innovation for the research on the topic of social media, similarly in another research conducted by Azeema and Nazuk (2017) used the grounded theory however Chang (2010) adopted the Diffusion of Innovation (DoI) for research explained twitter usage. In the current research theoretical perspective of diffusion of innovation, developed by Rogers (1961) will be used. It is defined as "the process by which an innovation is communicated through certain channels over time among the members of a social system". For its adopter, an innovation could be any "idea, practice, or object that is perceived as new by an individual or other unit of adoption" (Rogers, 2003). It is more reliable for requirement of Pakistani journalism setting and this theory facilitates the investigation of the competing dynamics of WhatsApp trending digital technology during certain time periods. Results of the study clearly identifying the integrating marketing related variables to examine the pattern of WhatsApp adoption behavior based on the impact of journalism. Conclusion assists in evaluating and analyzing the diffusion process of new digital technology and adopted trend of WhatsApp use among the journalists.

\subsection{Method}

To get the better understanding of the relationship between the ethical performance of the journalist and WhatsApp usage semi structured in-depth interview technique will be employed. Semi-structured interviews, is the technique though which researcher can reach an interactive discussion of respondents' personal oral communication (Lindlof, 2010) and theoretical framework based on the diffusion of innovation theory.

List of total registered journalist from journalist Union body was obtained for this research. Only those journalists were considered for the research who current affiliated with Rawalpindi or Islamabad based traditional media (TV Channel) as permanent employee with age of 24 to 36 years and using WhatsApp as tool for news. One private and one public traditional media were selected for the current research. Total 10 individuals including five field reporters, five newsroom persons were selected. the nature of research is qualitative which allows for small sample even single cases to acquire the depth of notion instead of bird eye view (Patton, 2002) An adapt Semi-structured interviews were conducted on the bases of previous research (Lasorsa at el., 2012).

On the bases of previous researches, questions were adapted for the current research in order to answer the ethical performance of the journalists including benefits of the individuals, needs and right of the journalists, collective goal with sub-heading of democracy, learning, participation, engagement, substantive message content over format and distribution. Ethical performance of the journalist identified the other side of the page which highlights the negative or unethical performance of the journalists. A section was also developed to answers these questions by using indirect approach.

\section{Results}

In current research to ten journalists were selected out of which 7 were male and 3 were female journalists, who are using WhatsApp and fall on developed criteria. 


\section{Total Journalists}

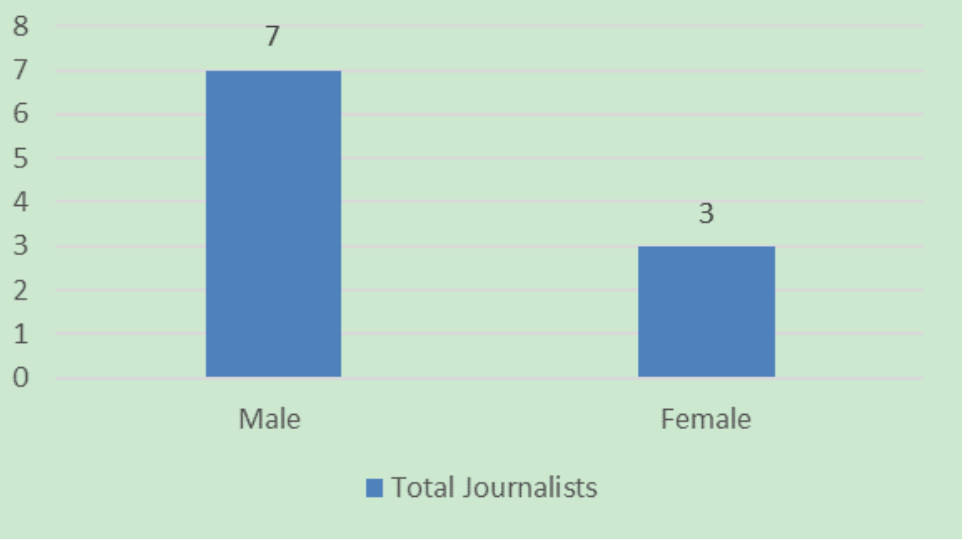

\subsection{Long-term benefits to the society}

A set of questions were asked from the journalists including one closed end question. The result of close end question shown in chart that every journalist was the part of long-term benefits of the society. However, the detail of in-depth interviews was different. $30 \%$ of the journalists not even understand the long-term benefits of the society. Only The $20 \%$ of the journalists work on the long-term society benefits and analysis show that $50 \%$ not consider long term benefits of society in field.

\section{Long Term benefits to the society}

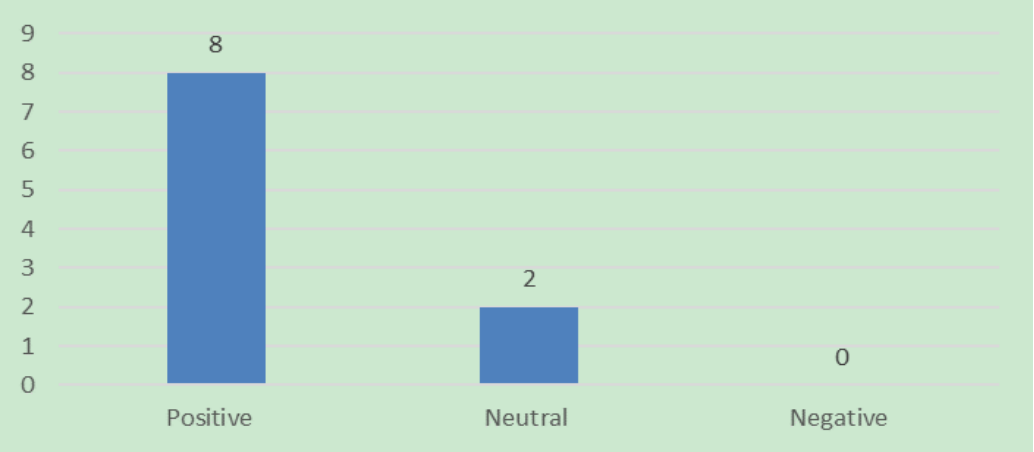

\subsection{Needs and rights}

Similarly, a set of questions were from the area related to needs and rights with one closed end question and results shows in chart form. The result indicate that journalists follow the criteria of needs and rights, however analysis of in-depth interview show that only $30 \%$ of the journalists keep in mind the needs and rights while reporting or on work. $70 \%$ of the journalists do not follow the journalists rule in field and focused on wants and choices.

\subsection{Needs and rights}

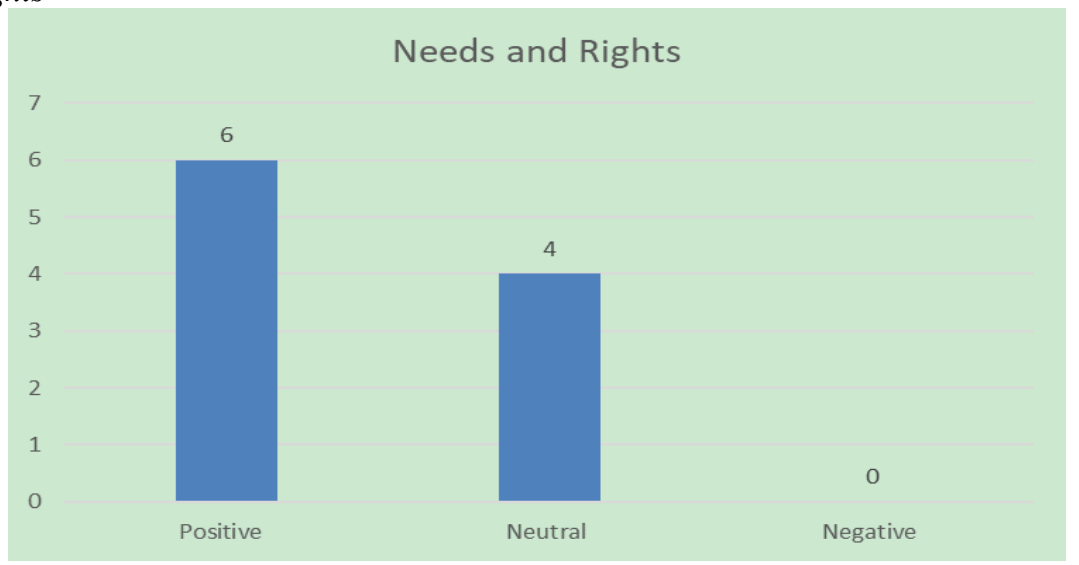




\subsection{Collective Goals}

The answer close ended question on collective goal was same as other and the analysis of the collective goal during the in-depth interview that collective goal shift from collective goal to individual and vice versa time to time bases. Only $10 \%$ strictly follow the collective goal criteria however $70 \%$ shift from individual to collective and collective to individual on the bases of situation. $20 \%$ most of the time not even bother collective goal during reporting or during work.

\section{Collective goal}

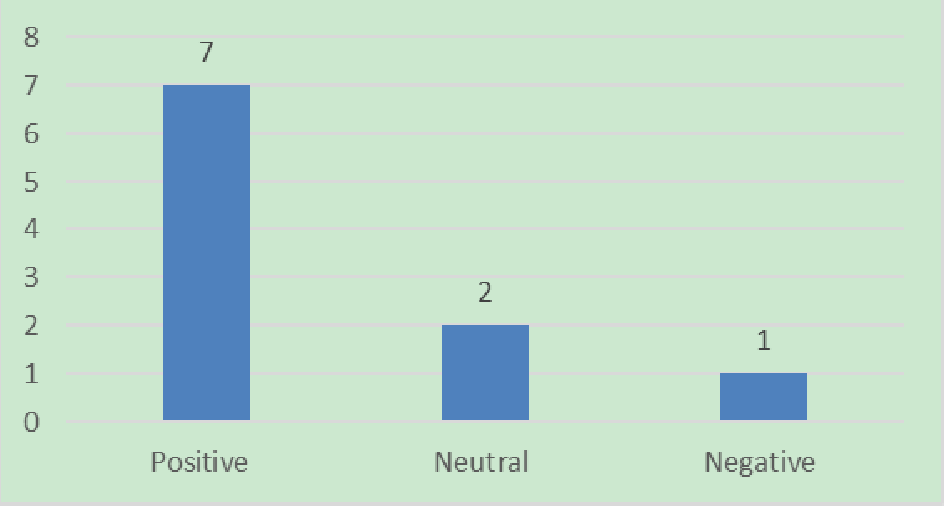

\subsection{WhatsApp Usage}

The last point of the ethical performance was the format and medium thorough which news disseminate, in this section the format of WhatsApp considered. As all the journalists are those who use WhatsApp for news gathering and information and are the part of different journalists' groups, for analysis of this part a set of questions were developed which show that some journalists consider it as credible and authentic source, while other use for speedy access. Journalists and reporters also used it for its easy to use feature. Sometime it helps to hide the source of news. Now a day $87 \%$ of journalists relay on Social media platform and out of which $90 \%$ used WhatsApp as source and tools to share and disseminate news between peer groups, newsrooms and their fan club. Sometime they event not read the complete news and forward. Similarly, most of the time they event not recheck the source or news detail.

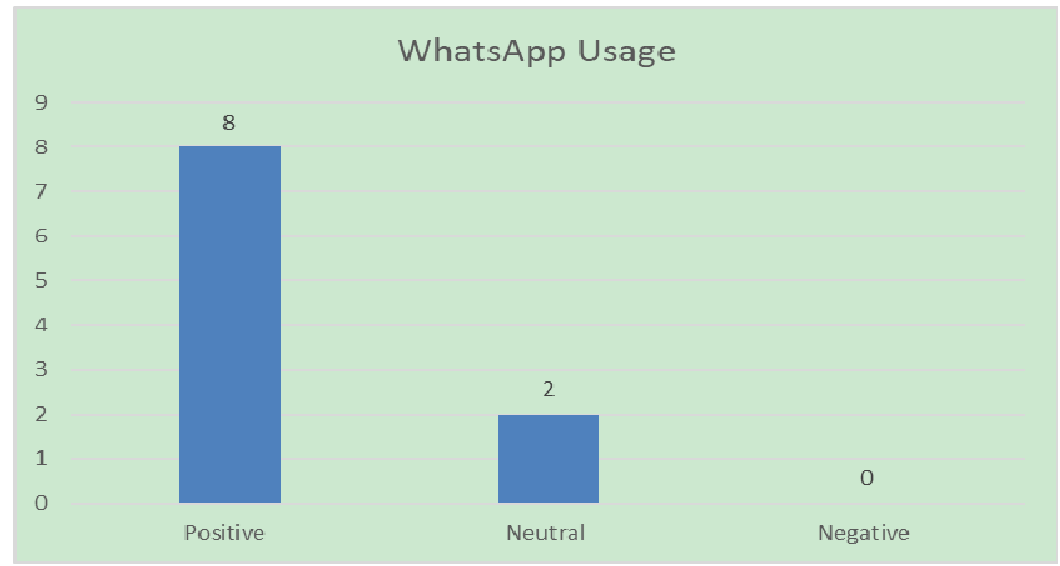

\section{Conclusion and Discussion}

In current research the main focus was to analysis WhatsApp usage which actually affects the journalist's performance especially ethical performance of the journalists. Research show that survey and close ended questions is not a proper way to identify the problem as most of the time journalists add false statements and exaggerate their throughs and practices as old researches also given the same. However, two ways to analysis this type result i.e the products that created after the best deliverable performance or by using in-depth interviews and adding some tricky questions. The results of current research show that journalists used WhatsApp because of its extra ordinary features that increase the quantity of reports and ultimately help to increase their increments. Sometime it used to share news as reports are in remote and far-flung area where live coverage is not possible or distraction between phone lines. Similarly, the sometime this medium used to facilitate their peer group without considering it is unethical journalistic approach. Results also indicate that the tool helps to share the same news at same time with news room, assignment desk, anchors, and analysts. The result also show that journalists and 
reporters know the rules and regulations of journalism and can easy follow it but most of the time they ignore this rule or priorities self-benefits on basic journalistic requirements. The ethical performance has four main factors in which journalists consider short term benefits of society and their own benefits instead of long-term benefits. Three main competitions are existing including competition between different traditional channels, competition between traditional and online media and competition between reporters and journalism. At initial stage competition between reporters and journalists are fruitful and motives them to create better reporting techniques. Online media and competition between the traditional media change into negative which ultimately lead to neglect and ignore rights of others, social contribution, collective contribution and long-term benefits. At this stage journalists and reporters focused on individual benefits, short-term goals, and contribution which only enhance their own profile. While share and disseminating news through WhatsApp, most of the time not event recheck the source and news detail. It also be observed that sometime they event not read the complete news and forward.

\section{REFERENCES}

Ahmad, A. N. (2010). Is Twitter a useful tool for journalists?. Journal of Media Practice, 11(2), 145-155.

Alsanie, S. I. (2015). Social Media (Facebook, Twitter, WhatsApp) Used, and it's Relationship with the University Students Contact with their Families in Saudi Arabia. Universal Journal of Psychology, 3(3), 6972.

Ashraf, S. A. B. N. (2014). Journalism ethics: Evidence from media industry of Pakistan.

Atkinson, J. (2011). Performance journalism: A three-template model of television news. The International Journal of Press/Politics, 16(1), 102-129.

Avery, E., Lariscy, R., \& Sweetser, K. D. (2010). Social media and shared —or divergent-uses? A coorientation analysis of public relations practitioners and journalists. International journal of strategic communication, 4(3), 189-205.

Azeema, N., \& Nazuk, A. WhatsApp and Journalism: News Practices of Pakistani Journalists.

Billings, A. C., Moscowitz, L. M., Rae, C., \& Brown-Devlin, N. (2015). The art of coming out: Traditional and social media frames surrounding the NBA's Jason Collins. Journalism \& Mass Communication Quarterly, 92(1), 142-160.

Bogle A. Guess which gender is more likely to be verified on Twitter? We'll wait. Mashable (2016, November 15). Retrieved November 13, 2017, from http://mashable.com/ 2016/11/15/ twitter-verification-womenmen/

Chang, H. C. (2010). A new perspective on Twitter hashtag use: Diffusion of innovation theory. Proceedings of the American Society for Information Science and Technology, 47(1), 1-4.

Edwards, V. (2016). Research skills for journalists. Routledge.

Garrison, B. (2001). Diffusion of online information technologies in newspaper newsrooms. Journalism, 2(2), 221-239.

Hansen, D. L., Shneiderman, B., \& Smith, M. A. (2010). Analyzing social media networks with NodeXL: Insights from a connected world. Morgan Kaufmann.

Hou, Y., \& Lampe, C. (2015, April). Social media effectiveness for public engagement: Example of small nonprofits. In Proceedings of the 33rd annual ACM conference on human factors in computing systems (pp. 3107-3116). ACM.

Hutchinson, J. (2015). Cultural nationalism. The Wiley Blackwell Encyclopedia of Race, Ethnicity, and Nationalism, 1-5.

International Research \& Exchange Board. (2014). Media sustainability index 2014: Europe and Eurasia. Washington, D.C.: IREX.

Kamel Boulos, M., Giustini, D., \& Wheeler, S. (2016). Instagram and WhatsApp in health and healthcare: an overview. Future Internet, 8(3), 37.

Kemp, S. (2018). Digital in 2018: Essential Insights Into Internet Social Media Mobile and Ecommerce Use Around the World. We Are Social.

Khan, A. (2017). Pakistani University Students Perspective on Whatsapp Usage: From the Lens of Uses \& Gratification Constructs. Volume 7, Issue No. 4 2017, 184.

Kietzmann, J. H., Hermkens, K., McCarthy, I. P., \& Silvestre, B. S. (2011). Social media? Get serious! Understanding the functional building blocks of social media. Business horizons, 54(3), 241-251.

Lin, K. Y., \& Lu, H. P. (2011). Why people use social networking sites: An empirical study integrating network externalities and motivation theory. Computers in human behavior, 27(3), 1152-1161.

Neuberger, C., vom Hofe, H. J., \& Nuernbergk, C. (2014). The use of Twitter by professional journalists: Results of a newsroom survey in Germany. Twitter and society, 345-357.

Patton, M. Q. (2002). Qualitative research and evaluation methods. Thousand Oaks. Cal.: Sage Publications.

Pintak, L., \& Nazir, S. J. (2013). Pakistani journalism: at the crossroads of Muslim identity, national priorities 
and journalistic culture. Media, Culture \& Society, 35(5), 640-665.

Pruto, R. (2016, Feb 3). The Gospel Herald TECHNOLOGY. WhatsApp Reaches One Billion Active Users One

Day Faster Than Gmail Did - See more at:

http://www.gospelherald.com/articles/61931/20160203/whatsapp-reaches-one-billion-active-users-oneday-faster-than-gmail-did

Rogers, E. M. (2003). The diffusion of innovation 5th edition.

Shah A. Avoid Posting 'fake' Items on Social Media. The New Indian Express. June 2018. Accessed July 2018. http://www.newindianexpress.com/nation/2018/jun/21/avoidposting-fake-items-on-social-media-amit-shahtells-bjpsworkers-1831635.html

Siapera, E., \& Veglis, A. (Eds.). (2012). The handbook of global online journalism. John Wiley \& Sons.

Silverman, C. (2016). This analysis shows how viral fake election news stories outperformed real news on Facebook. Buzzfeed News. Retrieved from https://www.buzzfeed.com/craigsilverman/viralfake-electionnews-outperformed-real-news-on-facebook?utm term=.todxjq3rN\#.qdmV4Ao3X

SINGER, JANE B. (2005) “The Political J-blogger: 'normalizing' a new media form to fit old norms and practices", Journalism 6(2), pp. 173_98.

SINGER, JANE B. (2007) "Contested Autonomy: professional and popular claims on journalistic norms", Journalism Studies 8(1), pp. 7995.

Siraj, S. A. (2009). Critical analysis of press freedom in Pakistan. Journal of Media and Communication Studies, 1(3), 043-047.

Taylor, P., \& Keeter, S. (2010). Millennials: Confident. Connected. Open to Change. Pew Research Center.

United Nations Educational, Scientific and Cultural Organization, Institute For Statistics (2012). The media landscape in 28 Countries: Results from a UIS pilot survey. Retrieved June 30, 2014, from http://www.uis.unesco.org/Communication/Documents/Media-statistics-pilot-survey-report.pdf

Wainaina, E. (2016, January 26). Kenya's Interior Ministry adopts WhatsApp to Boost Security and Public Interaction. (M. Gicheru, Ed.) Kenya: Techweez

Wolcott, P., \& Goodman, S. E. (2000). The internet in Turkey and Pakistan: a comparative analysis. 